\title{
Chapter 1 \\ Social Background and Adult \\ Socio-Demographic Outcomes \\ in a Cross-National Comparative \\ Perspective: An Introduction
}

\author{
Aart C. Liefbroer and Mioara Zoutewelle-Terovan
}

\subsection{A Shift in Narratives: From a Focus on Individualism to a Focus on Social Inequality}

For more than 30 years, what we would call an 'individual choice' paradigm has been dominant in social demographic thinking and empirical research on family formation processes in western, industrialized societies. Demographic behaviors such as decisions to leave the parental home, to start or end a partner relationship, and to have children were mainly viewed as the outcome of individual choices, based on young adults' own preferences.

This individual choice paradigm is not specific to demography, but has been dominant in the social sciences more general. Among sociologists, Inglehart (1977) suggested that many western societies experienced a cultural shift from a main reliance on materialist values to what he called postmaterialist values. By this, he meant a fundamental, 'intergenerational shift from an emphasis on economic and physical security toward an increased emphasis on self-expression, subjective well-being, and quality-of-life concerns' (Inglehart and Baker 2000, p. 26). Clearly, this shift in values and resulting individual preferences is linked to the rise of disposable income

\footnotetext{
A. C. Liefbroer $(\bowtie)$

Netherlands Interdisciplinary Demographic Institute (NIDI), The Hague, The Netherlands

Department of Epidemiology, University Medical Centre Groningen, University of

Groningen, Groningen, The Netherlands

Department of Sociology, Vrije Universiteit, Amsterdam, The Netherlands

e-mail: liefbroer@nidi.nl

M. Zoutewelle-Terovan

Netherlands Interdisciplinary Demographic Institute (NIDI), The Hague, The Netherlands

University of Groningen, Groningen, The Netherlands

e-mail: zoutewelle@nidi.nl
} 
and improved welfare arrangements in the post-World War II period. The greater economic security resulting from these changes, allowed birth cohorts to follow their own individualized, autonomy-oriented preferences to a much larger extent than in less economically secure times, as economic security could be taken for granted (Inglehart and Baker 2000). This emphasis on individual choice is also evident in the work of other influential sociologists like Giddens and Beck. Giddens (1991) stresses that choice has become a fundamental aspect of our daily life and that individuals plan their lives in line with their own biographical understanding. They actively engage in life-planning. Beck even suggests that individuals are condemned to individualization and that our time witnesses a new type of man - homo optionis. Nowadays we not only are able to make life choices, we cannot escape doing so (Beck and Beck-Gernsheim 2002). This focus on choice is also evident in other social science subfields. In youth studies, the idea that a standard life course has been replaced by a choice biography became popular (Du Bois-Reymond 1998), and within the life-course field, the concept of 'agency' became increasingly central (Elder 1994; Hitlin and Elder 2007).

Within demography, this 'individual choice' paradigm is most evident in the idea of the Second Demographic Transition, championed by Lesthaeghe and Van de Kaa (Lesthaeghe 2014; Lesthaeghe and Van de Kaa 1986; Van de Kaa 1987). They put forward the thesis that the family formation patterns of young adults have undergone a fundamental change since the 1960s. Events that limit individuals' autonomy (like marriage and parenthood) have been postponed or are more likely to be undone (like marriage), and behaviors that allow more self-expression (like living on one's own or in an unmarried rather than a married cohabitation) have become more popular. They clearly link this trend to the shift from materialistic to post-materialistic values that Inglehart has described (e.g. Van de Kaa 2001). Economic growth and technological innovations (e.g. in terms of contraceptives) made young adults less susceptible to normative points of view espoused by socializing agencies like the Church or the family. Instead, family formation decisions could be based more strongly on individual preferences related to self-expression and autonomy. Although the SDT has not been uncontested (Coleman 2004; Zaidi and Morgan 2017), it has been a key lens from which demographic decisions of young adults have been studied in the last three decades.

In the new millennium, and particularly during the last decade, the 'individual choice' paradigm has lost momentum and is increasingly being contested by what we would like to call the 'unequal choice' paradigm, that emphasizes the enduring and potentially growing role of social inequality. During the Great Recession, economic growth halted and even reversed in many western countries, the welfare state was restructured and inequality increased. The growing interest in this trend is seen most clearly in the reception of the work of Piketty (2014) in the social sciences.

But the idea of individual choice, as exemplified by the SDT, is also being increasingly contested in accounts of demographic changes. In our view, this occurred earlier and more profoundly in the USA than in Europe. First, there has always been a much stronger interest in the USA than in Europe in the demographic consequences of childhood disadvantage and social inequalities that originate in the 
parental home (Furstenberg et al. 1990; Kahn and Anderson 1992; McLanahan and Bumpass 1988; Wilson 1987). In the USA, the ideology of individual chances for upward mobility and the apparent discrepancy of this ideology with reality (Merton 1968), may have sparked continuous interest in the role of childhood disadvantage in socio-demographic outcomes. In Europe, in contrast, the emphasis on the role of the welfare state (and its aspect of relatively accessible public schooling) may have diminished the attention to social origin and fueled attention to what social disadvantages remain after completion of education (Esping-Andersen 1990; Hoem 1986). Second, the attention in the USA to the role of childhood disadvantage emphasized several dimensions of inequality that often intersect, like the class position of families, their racial make-up and the role of family dissolution. These multiple dimensions of childhood disadvantage all received extensive attention (Sassler et al. 2009; Smock and Schwartz 2020), and often in combination (Lichter and Crowley 2004). Probably most influential in this regard has been the work of Sara McLanahan. Within her Fragile Families project (e.g. Carlson et al. 2004; McLanahan and Percheski 2008) she and her co-workers tracked the lives of children born to unmarried parents in major cities in the USA. In addition, her Diverging Destinies idea suggested that the family outcomes of young adults have diverged between social classes during, and partly as a result of, the SDT (McLanahan 2004).

In Europe, this growing interest in the role of social inequality has manifested itself most clearly in the growing volume of work on the role of educational attainment in understanding patterns of the transition to adulthood (Nisén et al. 2020; Perelli-Harris et al. 2010; Wood et al. 2014). Theoretically, it has been most clearly articulated in the work of Perelli-Harris and her co-workers on the Patterns of Disadvantage in demographic behaviors (e.g. Perelli-Harris and Gerber 2011). A key line of reasoning is that demographic behaviors that have long been viewed as a sign of rejection of traditional family norms, like unmarried cohabitation and having children outside marriage, actually often are the consequence of a lack of resources to live up to traditional family norms. Thus, these behaviors are indicative of poor economic circumstances rather than of postmodern value orientations as suggested by the SDT. Another important theoretical line of reasoning is provided by the work of Blossfeld and his co-workers, who suggest that the process of globalization has led to increased economic insecurity among young adults, e.g. by increasing the likelihood of unemployment and temporary employment, hitting those with the lowest educational credentials the hardest (Blossfeld et al. 2005; Buchholz et al. 2009). Recently, this has led to a strong increase in empirical studies tracing the consequences of economic insecurity for family formation patterns (Vignoli et al. 2012; Vignoli et al. 2016).

Thus, although European demographers have engaged themselves with social inequalities in family formation patterns, they have mainly focused on inequalities stemming from achieved characteristics, in particular young adults' own level of education, rather than on inequalities stemming from ascribed characteristics, such as parents' level of education or the family structures children have experienced during childhood. As a result, the issue of how aspects of childhood disadvantage influence family formation patterns has received relatively little attention in the 
European demographic literature. In our view, this is quite puzzling. It might result from the idea that inequalities in social background are assumed not to matter anymore once inequalities in own socio-economic standing are taken into account. This seems to be the outcome of a combination of two ideas, viz. (1) that the educational system can eradicate social inequalities in social background and (2) that - if social background plays a role - it is only through the intergenerational transmission of educational opportunities. Both these ideas are clearly false. Educational outcomes are still very much socially stratified (Bukodi and Goldthorpe 2013) and parental social class matters for many demographic outcomes even if own social background as a mediating process is accounted for (see references in Chap. 2 to Chap. 6). Thus, in our view, a stronger focus on how ascribed aspects of inequality influence demographic decision-making during young adulthood is warranted.

In addition, it could very well be that the consequences of childhood disadvantage are not restricted to young adulthood itself, but last way longer into later life. Partially, this 'long arm' of childhood disadvantage could even run through young adults' demographic behaviors (Harden et al. 2009; Hobcraft and Kiernan 2001; Kalmijn and Monden 2010; Sigle-Rushton et al. 2005; Wolfe 2009). This leads to the question to what extent childhood disadvantage and poor demographic choices determine poor socio-economic, social and health outcomes in later phases of the life course, such as low income, unemployment, loneliness and poor health?

Thus, a first aim of this book is to examine to what extent childhood disadvantage plays a role in understanding socio-demographic outcomes in adulthood and subsequent social, economic and health outcomes later in life. This is schematically illustrated in arrows A, B and C in Fig. 1.1. One focus will be on the manner in which childhood disadvantage influences the occurrence, timing and sequencing of young adult demographic behaviors (arrow A). A second focus will be on how

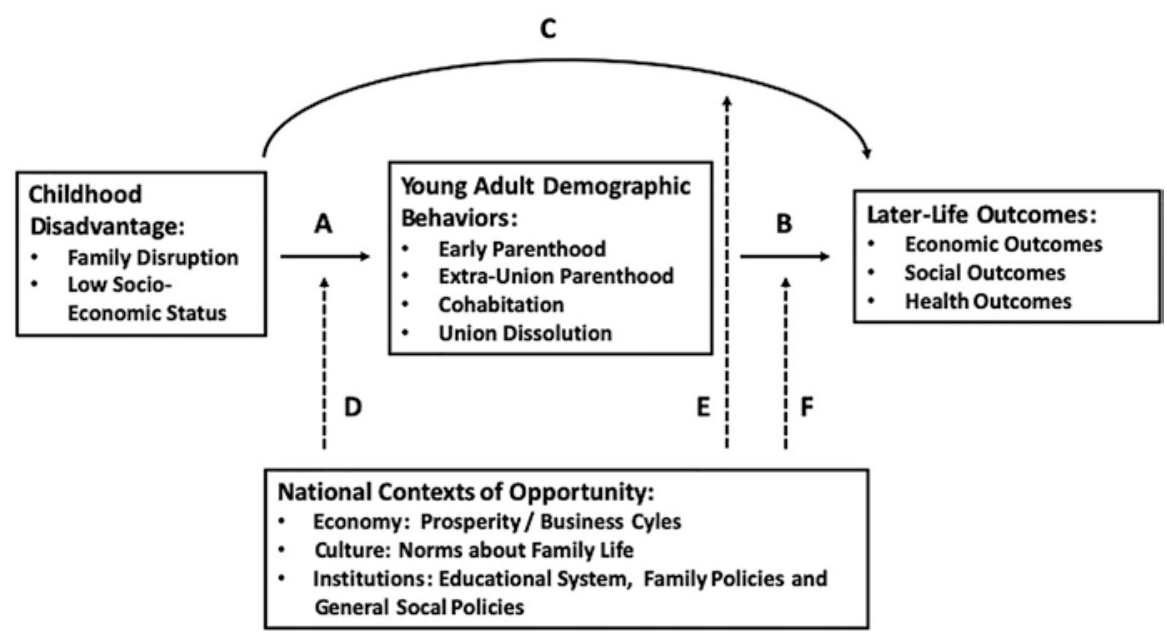

Fig. 1.1 A model of the relationships between childhood disadvantage, young adult demographic behavior, later-life outcomes and contexts of opportunity 
childhood disadvantage influences later-life outcomes, both directly (arrow C) and indirectly through demographic events (arrow B).

To understand these links in reproducing inequalities, we combine insights from two perspectives, the resource perspective (Hobfoll 2002) and the life-course perspective (Elder Jr. et al. 2003). Both in sociology and psychology, the availability of resources is seen as essential to realize main goals in life, such as physical and psychological well-being. In sociology, the importance of several types of resources or forms of 'capital' - for people's life chances is a central topic of interest. A key distinction between economic and cultural capital goes back to Weber (1968 [orig. 1922]) and Bourdieu (1984 [orig. 1979]), and figures prominently in stratification (De Graaf and Kalmijn 2001) and poverty research (Corcoran 1995). Economic capital refers to income and financial assets that people have at their disposal to improve their life chances, and cultural capital refers to lifestyles, norms and skills that they can use to improve their life chances. In addition to these two types of capital, social capital is often distinguished as a third major type of capital (Granovetter 1973). Examples of social capital that can improve children's life chances are appropriate parental supervision (Grolnick and Pomerantz 2009; Kiernan and Mensah 2011), friendship networks with children with a higher-class background (Prinstein and Dodge 2008), and access to people with knowledge about local labor markets (Granovetter 1973). In psychology, a prominent idea is that resources are of prime importance for realizing well-being (Diener and Fujita 1995): the more resources people have at their disposal the more they will be able to realize goals that contribute to well-being. In addition to the types of resources stressed in sociological discourse, psychologists emphasize the importance of personal resources - such as self-esteem, coping strategies and planful competence - to realize these goals (Clausen 1991; Hobfoll 2002).

The resource perspective offers a framework to understand both the relationship between childhood circumstances and demographic behavior in young adulthood and the relationship between these demographic behaviors and later-life outcomes. It suggests that the occurrence and timing of demographic events in young adulthood depends on the resources that are available. Low levels of resources will enhance the chances that young adults will make demographic decisions that offer short-term benefits but may negatively affect their longer-run well-being - such as early union formation and parenthood. Low levels of resources may also increase the risk that young adults will not be able to maintain potentially well-being enhancing relationships. In other words, a disadvantaged background leads to young adults having few resources at their disposal, and this - in its turn - will increase the risk of making demographic decisions that have potentially negative consequences for well-being. But the resource perspective can also elucidate the relationship between young-adult demographic behavior and later-life outcomes, because it implies that demographic behaviors have consequences for the maintenance and future acquisition of additional resources. Some demographic behaviors can increase people's resources, whereas others negatively affect resources. Demographic events that reduce people's resources will have a negative effect on their future life chances and well-being, whereas events that increase their resources will have a positive effect. 
Thus, the resource perspective suggests that the availability of resources - economic, cultural, social, or personal - influences the occurrence and timing of demographic events in young adulthood, and that the occurrence and timing of these events in their turn influences the future levels of resources that people have at their disposal to realize later-life goals.

To fully appreciate the role of demographic events in the reproduction of inequality (arrow B), the resource perspective has to be complemented by a life-course perspective (Elder 1994; Elder Jr. et al. 2003; Settersten Jr. and Mayer 1997). An important insight of the life-course perspective is that the consequences of demographic events for people's future life chances depend on their timing, on their relationship with events in other life-course domains, on the reactions by significant others, on the amount of time that has passed since the event occurred, and on the content and order of subsequent events. First, events can occur on- or off-time (Settersten Jr. and Hagestad 1996). Events are on-time when their timing is in line with what is common in a certain society or social group, whereas they are off-time if the timing does not correspond to common time-tables. Apart from the fact that off-time events may be disapproved off more than on-time ones and that off-time events often have more serious repercussions for other life domains than on-time events, another potential drawback of off-time events is that no clear scripts for offtime events are available that can guide people in how to deal with the event. This often worsens the already negative consequences of specific off-time demographic events. Second, demographic events often have direct or indirect repercussions for events in other life domains (Aassve et al. 2006). For instance, if one has a child while still enrolled in school, this will often lead to dropping-out of school and to a lower level of educational attainment (Klepinger et al. 1995). This will have negative consequences for one's future earnings. For women, having children or entering a partner relationship often lead to a reduction in working hours - or sometimes even to a withdrawal from the labor market altogether (Del Boca et al. 2008). Divorce, on the other hand, may lead to re-entry into the labor market, but often at relatively low levels - either because women can only work part-time in order to combine parenthood and employment or because their human capital has depreciated as a result of prolonged absence from the labor market (Van Damme et al. 2009). Third, some demographic events may be normatively approved off, whereas other are met with disapproval (Liefbroer and Billari 2010). If people experience events that are disapproved off, they might be confronted with sanctions or become stigmatized. Examples of demographic behaviors that can be met with disapproval are divorce (especially if the couple has young children), unmarried cohabitation, and having children outside a stable union (Liefbroer and Fokkema 2008). Ironically, also the non-occurrence of expected demographic events, like voluntary childlessness, could be met with sanctions, and thus negatively influence people's future life chances (Merz and Liefbroer 2012). Fourth, to some degree, the negative effects of demographic events may wane as time goes by, for instance because people learn to adjust to a new lifestyle, stigma wears off, or attachment to the labor market is regained (Lucas 2007; Peters and Liefbroer 1997). Thus, it could be expected that the negative impact of events becomes smaller the more time has elapsed since the 
negative event occurred. Fifth, negative effects of demographic events may be mitigated or strengthened by subsequent life events. Theories of cumulative disadvantage (Crystal and Shea 1990; Dannefer 2003) suggest that adverse events increase the risk of subsequent adverse events and thus lead to an accumulation of negative circumstances that eventually result in seriously worsened late-life outcomes. For instance, if young adults who have experienced a union dissolution find a new partner, part or all of the negative effects of union dissolution may be redressed. However, it could also be that an accumulation of negative life events occurs, for instance because young adults with a young child enter into a new relationship too fast and are more prone to experience another union dissolution.

In combination, the resource perspective and the life-course perspective suggest that: (a) the availability of resources influences the occurrence, timing and sequencing of demographic events in young adulthood, and (b) that these events in themselves lead to further changes in the availability of resources. To what extent demographic events lead to a change in the availability of resources, and to what extent this influences later-life outcomes depends on the timing and patterning of these events.

\subsection{Studying Social Inequality in Socio-Demographic Outcomes in Comparative Perspective}

As the review of the literature in the previous section makes clear, there is an abundance of empirical evidence that childhood disadvantage influences the adult life course. However, a marked limitation of most existing research is that it examines these relationships within one societal context only. In some countries the potentially negative consequences of inequalities are probably more readily buffered than in others. Within demography, a lot of effort has been invested in examining crossnational differences in demographic outcomes (Frejka and Sobotka 2008; Sobotka et al. 2011), and to a lesser degree to which extent the influence of young adults' own educational credentials is linked to socio-demographic outcomes (Härkönen and Dronkers 2006; Perelli-Harris et al. 2010; Wood et al. 2014). However, attention to cross-national differences in the consequences of childhood disadvantage for socio-demographic outcomes has been very limited. This issue is central to this book. Our contention is that societal contexts matter. The resource perspective discussed above suggests that the availability of resources influences demographic behaviors in young adulthood and later-life outcomes and that children growing up disadvantaged usually have fewer resources at their disposal than children growing up in more fortunate circumstances. If so, societal contexts that are more generous in supplementing resources and offering opportunities to families that are lacking them will probably show weaker links between childhood disadvantage and adult outcomes than societies that are less generous in this regard. The key contribution of this book is that it examines this contextual variation and focuses on one general 
explanation for this contextual variation: the strength of the relationships depends on the opportunities that the context offers to abate the adverse impact of economic and social deprivation. Contexts that offer good opportunities to people to escape situations of deprivation (e.g. social security systems that offer financial support to people in financial jeopardy, educational systems that stimulate upward mobility, normative systems that do not stigmatize people with deviant behaviors, and economic prosperity) are expected to weaken the links between childhood disadvantage, young adult demographic behavior, and later-life outcomes.

The 'contexts of opportunity hypothesis' posits that contexts that offer opportunities to young children, young adults, and their families to improve their life situation in terms of the availability of economic, cultural, social and personal resources will weaken the links between childhood disadvantage, demographic behavior and later-life outcomes. This 'contexts of opportunity' hypothesis is a general hypothesis that applies to all types of contexts. It could be used to study temporal changes in the links between childhood disadvantage, young adult demographic behavior and later-life outcomes within one specific geographical unit, as contexts can change over time, for instance as a result of policy interventions or as a result of exogenous change in economic or cultural circumstances. It could, however, also be used to study differences in these links across geographical units at one point in time, as the strength of these links might depend on geographical differences in economic, cultural or institutional contexts. The importance of the geographical dimension has been stressed by geographers in the 'geography of opportunity' literature (Galster and Killen 1995; Rosenbaum et al. 2002). In that literature, the emphasis is on variation in opportunities at the level of neighborhoods. However, one could also study contextual variation at higher scale levels, like towns, regions, or countries. In this book, the emphasis is on differences in contexts of opportunity at the level of nation states. The choice for a focus on the country level is based to a large extent on the fact that it is the most appropriate level to test the potential role of government policies. In addition, variation in economic and cultural factors is also often larger at the country level than at lower geographical levels.

In studying geographical and temporal variation, we pay attention to three types of national 'contexts of opportunity'. First, the general economic situation is expected to be important (Fischer and Liefbroer 2006). In times or in places with poor overall economic prospects, those with a bad starting position are usually hit hardest by an adverse economic climate (Fallon and Lucas 2002). Therefore, the better the economic situation is, the weaker the links between childhood disadvantage, young adult demographic behavior and later-life outcomes will be. Second, cultural factors are expected to be important. In particular, norms and attitudes concerning family life and social disadvantage are deemed to be crucial (Soons and Kalmijn 2009). In societies where people in disadvantaged positions - the poor, the unemployed, single parents, the divorced, etc. - are stigmatized, it will be more difficult for the disadvantaged to escape their situation, either as a result of covert discrimination or as a result of the disadvantaged themselves developing a low selfimage (Major and O'Brien 2005). Thus, the less deviant behavior is stigmatized, the weaker the links between childhood disadvantage, young adult demographic 
behavior and later-life outcomes are expected to be. Third, institutional arrangements are expected to matter (e.g. Del Boca et al. 2008; Uunk 2004; Van Damme et al. 2009). For instance, the openness of the educational system is important. The lower the financial hurdles within an educational system are, and the better prepared that system is to reduce initial differences in cultural resources - e.g. by low levels of tracking -, the more likely it is that an educational system will stimulate upward mobility among those of a disadvantaged social background (Hanuschek and Wössmann 2006; Pfeffer 2008). Thus, the more open an educational system is, the weaker the links between childhood disadvantage, young adult demographic behavior and later-life outcomes are expected to be. Family policies and general social policies also are important institutional factors. Policies that support families and people in disadvantaged situations may facilitate them or their children to escape poverty or to dampen the most adverse consequences of social disadvantage (Esping-Andersen 1990; Bäckman 2009). Therefore, the better the welfare system buffers social risks, the weaker the links between childhood disadvantage, young adult demographic behavior and later-life outcomes are expected to be.

Thus, the second aim of this book is to examine the 'contexts of opportunity' hypothesis. The role of societal contexts is graphically illustrated in Fig. 1.1. The arrows D, E and F in represent how individual effects discussed in the previous section differ across national contexts of opportunity. Economic, cultural and institutional contexts of opportunities are expected to moderate the links between childhood disadvantage, young adult demographic behavior, and later life outcomes. All chapters in this book focus on different aspects of this relationship.

\subsection{Outline of the Book}

Next to the introductory chapter (Chap. 1), this book contains 8 additional chapters providing theoretical, empirical and methodological insights with great value for the life-course framework and cross-national comparative research. The first three chapters (Chap. 2, 3 and 4) focus on the link between childhood disadvantage and family transitions in young adulthood. Chapter 5 concentrates on well-being outcomes in later-life (socio-emotional and economic) and the manner in which they are influenced by family-related experiences in young and mid adulthood. Chapters 6 and 7 are methodological chapters introducing novel analytical techniques with great applicability for research using hierarchically nested data structures (often the case in cross-national comparative research) and testing causal mechanisms in lifecourse analysis. Chapter 8 provides theoretical reflections on the reproduction of social inequality throughout the life course. The final chapter, Chap. 9, displays an overview of all research conducted within the CONOPP project, the lessons learned from empirically studying cross-national variation in the stratification of demographic behavior, as well as suggestions for future progress in understanding demographic processes. A short description of the content of each chapter can be found below. 
In Chap. 2, Brons concentrates on explaining the social stratification of union formation and union dissolution. This chapter provides valuable knowledge for lifecourse theory and research by revealing the role of parental socio-economic status reflecting a (dis)advantaged background - in explaining the timing and type of union dynamics. Moreover, this chapter provides unprecedented evidence on crossnational variation in the association between parental SES and union dynamics, and tests of whether the advancement of a country in the SDT (measured by the prevalence of cohabitation or divorce rate) explains the observed variation. The general conclusion is that a higher parental SES delays entrance into a co-residential union, that the delaying effect is stronger for married individuals than for cohabiters, and that such parental background increases the risk of union dissolution. Moreover, the impact of parental SES on union dynamics varies considerably across countries and family disadvantage plays a less important role in more individualistic or economically developed countries - possibly because one's family-related transitions are less connected to values and resources of the family of origin.

In Chap. 3, Koops also studies the manner in which parental SES affects union formation but she focuses on the partnership context around entrance into parenthood. In this chapter she covers three major topics. First, she studies the effect of parental SES on partner status (single, cohabiting or married) at first birth and distinguishes between direct and indirect effects (with the indirect effects transmitted through one's own education). Second, Koops studies the link between social background and fertility not only for females (as most previous studies do), but also for males. Third, she studies cross-national variation in effects using data on European and North-American countries. The results presented in this chapter provide support for the Pattern of Disadvantage framework as women with lower SES are more likely to have a birth within cohabitation or while being single than within marriage. Interestingly, Koops finds minimal differences between men and women in the effect of social background on the likelihood of having a first birth within marriage or cohabitation. Particularly interesting are the results showing considerable crossnational differences in the effects investigated (with countries differing in the way parental SES directly affects partnership context or is transmitted intergenerationally through one's own SES).

In Chap. 4, Mooyaart concentrates on two topics. First, he provides evidence for contextual differences in the role of socio-economic background on family formation behavior in young adulthood (union formation and entry into parenthood). His research is unique as it studies context: (a) in a historical perspective (changes in effects over time starting with the 1930s); (b) across the life course (changes with age over the young adult period); and (c) in a cross-national comparative (comparing effects across different nations). Particularly interesting in Mooyaart's research is the holistic approach in investigating family formation - as pathways reflecting successions of events defined by their type, timing, quantum and duration. Second, next to family formation behavior, he investigates economic stratification in young adulthood and expands current understanding regarding the consequences of a disadvantaged family background on income trajectories. His analyses reveal that, although family formation patterns have changed over time, parental 
socio-economic background continues to stratify family formation pathways, and that over time the divide between social classes in family formation patterns increased. Such results align with the Pattern of Disadvantage and Diverging Destinies arguments. He also finds evidence that the impact of parental SES persists throughout young adulthood, but that it becomes weaker over time and differs per type of union (marriage vs cohabitation). The investigation of economic context in young adulthood reveals that socio-economic disadvantages in the family of origin negatively affect young adults' economic position via the manner in which they develop their career and family pathways.

In Chap. 5, Zoutewelle-Terovan and Muller focus on outcomes in later life phases (mid and late adulthood) and explain the manner in which later-life socio-emotional and economic well-being (loneliness, employment and income) are influenced by family-related events (e.g. union formation, parenthood) occurring earlier in life. Their research advances knowledge on the topic on at least three important aspects. First, they observe transitions in the family domain through the lens of social customs and provide evidence on the manner in which non-normative family behaviors (e.g. non-transitions, off-time transitions, non-standard trajectories) affect later-life well-being outcomes. Second, they provide evidence on cross-national variation in the effects investigated by analyzing a wide range of European countries. Finally, their analyses on cross-national variation do not stop at exposing heterogeneity, but further try to explain variation through culturally-embedded norms and values regarding family formation and national economic circumstances. In a nutshell, the authors argue for the presence of a "non-normative family penalty for loneliness" (as the loneliest individuals in later-life are the ones who do not experience family transitions or postpone such events) and a "non-normative family bonus for women's economic outcomes" (as non-transitions in the family domain are linked to better economic circumstances in later life). Moreover, in their research, countrylevel indicators such as traditional family norms and female labor force participation during child-rearing years were able to explain only a part of the cross-national variation in the link between family-related experiences and later-life well-being.

Chapter 6 is a methodological chapter in which Liefbroer and ZoutewelleTerovan discuss the analysis of hierarchically nested data structures with two levels of analysis and a small level-2 sample size. The chapter starts with a discussion on the use of multilevel modeling in the analysis of nested data and discusses estimation biases when analyzing a low number of level-2 units. Further, the authors offer an overview of alternative techniques to multilevel modeling and explain several limitations of these alternatives in the context of cross-national comparative research. However, the main goal of the chapter is to introduce a new method of analysis - the 2-step meta-analytical approach - allowing to test hypotheses similarly to hypotheses tested in multilevel models and providing reliable estimates even when few countries are analyzed. The method is illustrated for both continuous and binary dependent variables and results are compared to the classic multilevel approach. The applicability of the method is not restricted to cross-national research, but extends to any research using nested data with few level-2 units. 
In Chap. 7, Han and Elzinga focus on modeling causal chains in the life course of individuals. As life-course research to date mainly focuses on classifying lifecourse patterns and understanding the manner in which they explain later-life outcomes, it remains difficult to properly understand the driving forces that generate the chain of consecutive events. In this chapter, the authors discuss the validity of life-course generating models and the minimum requirements to accomplish that. They argue that methods currently used in life-course research do not satisfy all requirements, and propose the use of Hidden Markov Models in modeling the generative mechanisms involved. They demonstrate the value of such models by applying them to transitions in different life-course domains (education, family, work).

In Chap. 8, Hiekel focuses on theoretical mechanisms explaining the intergenerational transmission of social inequality in demographic behavior. The aim of this chapter is threefold. First, the author provides an overview of various theoretical models of transmission explaining the manner in which childhood disadvantage shapes individuals' life courses in adulthood. The contrast between economic and cultural perspectives in explaining social inequality is central. Second, she discusses the theoretical implications of the findings emerged from the CONOPP project. The final part of the chapter includes suggestions for future research aiming to push boundaries in understanding mechanisms of intergenerational social inequality.

In the final chapter of the book, Chap. 9, Liefbroer discusses key issues related to the study of social inequalities in a cross-national perspective. First, he presents the central theoretical frameworks that can be used to derive hypotheses on crossnational differences in the relationship between youth disadvantage and family formation. Further, he focuses on methodological challenges scholars may be confronted with in studying cross-national differences in effects. Finally, he presents an overview of the main findings within the CONOPP project, draws some final conclusions on the reproduction of inequality across the life-course and makes suggestions for future empirical endeavors.

Acknowledgements The research leading to these results has received funding from the European Research Council under the European Union's Seventh Framework Programme (FP/2007-2013)/ ERC Grant Agreement n. 324178.

\section{References}

Aassve, A., S. Burgess, C. Propper, and M. Dickson. 2006. Employment, family union and childbearing decisions in Great Britain. Journal of the Royal Statistical Society A 169 (4): 781-804.

Bäckman, O. 2009. Institutions, structures and poverty: A comparative study of 16 countries, 1980-2000. European Sociological Review 25 (2): 251-264.

Beck, U., and E. Beck-Gernsheim. 2002. Individualization. Institutionalized individualism and its social and political consequences. London: Sage.

Blossfeld, H.-P., E. Klijzing, M. Mills, and K. Kurz. 2005. Globalization, uncertainty and youth in society. London: Routledge.

Bourdieu, P. 1984. Distinction. A social critique of the judgement of taste. London: Routledge. 
Buchholz, S., D. Hofäcker, M. Mills, H.-P. Blossfeld, K. Kurz, and H. Hofmeister. 2009. Life courses in the globalization process: The development of social inequalities in modern societies. European Sociological Review 25 (1): 53-71.

Bukodi, E., and J.H. Goldthorpe. 2013. Decomposing 'social origins': The effects of parents' class, status, and education on the educational attainment of their children. European Sociological Review 29 (5): 1024-1039.

Carlson, M., S. McLanahan, and P. England. 2004. Union formation in fragile families. Demography 41 (2): 237-261.

Clausen, J.S. 1991. Adolescent competence and the shaping of the life course. American Journal of Sociology 96 (4): 804-842.

Coleman, D. 2004. Why we don't have to believe without doubting in the 'Second Demographic Transition': Some agnostic comments. Vienna Yearbook of Population Research 2: 11-24.

Corcoran, M. 1995. Rags to rags: Poverty and mobility in the United States. Annual Review of Sociology 21 (1): 237-267.

Crystal, S., and D. Shea. 1990. Cumulative advantage, cumulative disadvantage and inequality among elderly people. The Gerontologist 30 (4): 437-443.

Dannefer, D. 2003. Cumulative advantage/disadvantage and the life course: Cross-fertilizing age and social science theory. Journal of Gerontology: Social Sciences 58 (6): S327-S337.

De Graaf, P.M., and M. Kalmijn. 2001. Trends in the intergenerational transmission of cultural and economic status. Acta Sociologica 44 (1): 51-66.

Del Boca, D., S. Pasqua, and C. Pronzato. 2008. Motherhood and market work decisions in institutional context: A European perspective. Oxford Economic Papers 61: i147-i171.

Diener, E., and F. Fujita. 1995. Resources, personal strivings, and subjective well-being: A nomothetic and ideographic approach. Journal of Personality and Social Psychology 68 (5): 926-935.

Du Bois-Reymond, M. 1998. 'I don't want to commit myself yet': Young people's life concepts. Journal of Youth Studies 1 (1): 63-79.

Elder, G.H. 1994. Time, human agency, and social change: Perspectives on the life course. Social Psychology Quarterly 57 (1): 4-15.

Elder, G.H., Jr., M. Kirkpatrick Johnson, and R. Crosnoe. 2003. The emergence and development of life course theory. In Handbook of the life course, ed. J.T. Mortimer and M.J. Shanahan, 3-19. New York: Kluwer Academic/Plenum Publishers.

Esping-Andersen, G. 1990. The three worlds of welfare capitalism. Oxford: Polity Press.

Fallon, P.R., and R.E.B. Lucas. 2002. The impact of financial crises on labor markets, household incomes and poverty: A review of evidence. The World Bank Research Observer 17 (1): 21-45.

Fischer, T.F.C., and A.C. Liefbroer. 2006. For richer, for poorer. The impact of macro-economic conditions on union dissolution rates in the Netherlands 1972-1996. European Sociological Review 22 (5): 519-532.

Frejka, T., and T. Sobotka. 2008. Fertility in Europe: Diverse, delayed and below replacement. Demographic Research 19 (3): 15-46.

Furstenberg, F.F., J.A. Levine, and J. Brooks-Gunn. 1990. The children of teenage mothers: Patterns of early childbearing in two generations. Family Planning Perspectives 22 (2): 54-61.

Galster, G., and S. Killen. 1995. The geography of metropolitan opportunity: Housing mobility and the many faces of social capital. Housing Policy Debate 9: 177-221.

Giddens, A. 1991. Modernity and self-identity. Self and society in the late modern age. Cambridge: Polity Press.

Granovetter, M.S. 1973. The strength of weak ties. American Journal of Sociology 78: 1360-1380.

Grolnick, W.S., and E.M. Pomerantz. 2009. Issues and challenges in studying parental control: Toward a new conceptualization. Child Development Perspectives 3 (3): 165-170.

Hanuschek, E.A., and L. Wössmann. 2006. Does educational tracking affect performance and inequality? Differences-in-differences evidence across countries. The Economic Journal 116 (510): C63-C76.

Harden, A., G. Brunton, A. Fletcher, and A. Oakley. 2009. Teenage pregnancy and social disadvantage: Systematic review integrating controlled trials and qualitative studies. British Medical Journal 339: b4254. 
Härkönen, J., and J. Dronkers. 2006. Stability and change in the educational gradient of divorce. A comparison of seventeen countries. European Sociological Review 22 (5): 501-517.

Hitlin, S., and G.H. Elder. 2007. Time, self, and the curiously abstract concept of agency. Sociological Theory 25 (2): 170-191.

Hobcraft, J., and K. Kiernan. 2001. Childhood poverty, early motherhood and adult social exclusion. British Journal of Sociology 52 (3): 495-517.

Hobfoll, S.E. 2002. Social and psychological resources and adaptation. Review of General Psychology 6 (4): 307-324.

Hoem, J.M. 1986. The impact of education on modern family-union initiation. European Journal of Population 2 (2): 113-133.

Inglehart, R. 1977. The silent revolution. Changing values and political styles among Western publics. Princeton: Princeton University Press.

Inglehart, R., and W.E. Baker. 2000. Modernization, cultural change, and the persistence of traditional values. American Sociological Review 65 (1): 19-51.

Kahn, J.R., and K.E. Anderson. 1992. Intergenerational patterns of teenage fertility. Demography 29 (1): 39-57.

Kalmijn, M., and C. Monden. 2010. Poverty and union formation among never-married single mothers in the Netherlands, 1989-2005. Population Studies 64 (3): 263-274.

Kiernan, K.E., and F.K. Mensah. 2011. Poverty, family resources and children's early educational attainment: The mediating role of parenting. British Educational Research Journal 37 (2): 317-336.

Klepinger, D.H., S. Lundberg, and R.D. Plotnick. 1995. Adolescent fertility and the educational attainment of young women. Family Planning Perspectives 27: 23-28.

Lesthaeghe, R. 2014. The second demographic transition: A concise overview of its development. Proceedings of the National Academy of Sciences 111 (51): 18112-18115.

Lesthaeghe, R., and D.J. Van de Kaa. 1986. Twee demografische transities? In Bevolking: groei en krimp, ed. D.J. Van de Kaa and R. Lesthaeghe, 9-24. Deventer: Van Loghum Slaterus.

Lichter, D.T., and M.L. Crowley. 2004. Welfare reform and child poverty: Effects of maternal employment, marriage, and cohabitation. Social Science Research 33 (3): 385-408.

Liefbroer, A.C., and F.C. Billari. 2010. Bringing norms back in: A theoretical and empirical discussion of their importance for understanding demographic behaviour. Population, Space and Place 16 (4): 287-305.

Liefbroer, A.C., and T. Fokkema. 2008. Recent trends in demographic attitudes and behaviour: Is the second demographic transition moving to Southern and Eastern Europe? In Demographic challenges for the 21 st century. A state of the art in demography, ed. J. Surkyn, P. Deboosere, and J. van Bavel, 115-141. Brussel: Vrije Universiteit Press.

Lucas, R.E. 2007. Adaptation and the set-point model of subjective well-being: Does happiness change after major life events? Current Directions in Psychological Science 16 (2): 75-79.

Major, B., and L.T. O'Brien. 2005. The social psychology of stigma. Annual Review of Psychology 56: 393-421.

McLanahan, S. 2004. Diverging destinies: How children are faring under the second demographic transition. Demography 41 (4): 607-627.

McLanahan, S., and L. Bumpass. 1988. Intergenerational consequences of family disruption. American Journal of Sociology 94 (1): 130-152.

McLanahan, S., and C. Percheski. 2008. Family structure and the reproduction of inequalities. Annual Review of Sociology 34 (1): 257-276.

Merton, R.K. 1968. Social theory and social structure. 1968 enlarged edition. New York: The Free Press.

Merz, E.-M., and A.C. Liefbroer. 2012. The attitude toward voluntary childlessness in Europe: Cultural and institutional explanations. Journal of Marriage and Family 74 (3): 587-600.

Nisén, J., S. Klüsener, J. Dahlberg, L. Dommermuth, A. Jasilioniene, M. Kreyenfeld, T. Lappegård, P. Li, P. Martikainen, K. Neels, and B. Riederer. 2020. Educational differences in cohort fertility across sub-national regions in Europe. European Journal of Population: 1-33. 
Perelli-Harris, B., and T.P. Gerber. 2011. Nonmarital childbearing in Russia: Second demographic transition or pattern of disadvantage? Demography 48 (1): 317-342.

Perelli-Harris, B., W. Sigle-Rushton, M. Kreyenfeld, T. Lappegård, R. Keizer, and C. Berghammer. 2010. The educational gradient of childbearing within cohabitation in Europe. Population and Development Review 36 (4): 775-801.

Peters, A., and A.C. Liefbroer. 1997. Beyond marital status: Partner history and well-being in old age. Journal of Marriage and the Family 59: 687-699.

Pfeffer, F.T. 2008. Persistent inequality in educational attainment and its institutional context. European Sociological Review 24: 543-565.

Piketty, Th. 2014. Capital in the twenty-first century. Cambridge: Harvard University Press.

Prinstein, M.J., and K.A. Dodge. 2008. Understanding peer influence in children and adolescents. New York: The Guilford Press.

Rosenbaum, J.E., L. Reynolds, and S. DeLuca. 2002. How do places matter? The geography of opportunity, self-efficacy and a look inside the black box of residential mobility. Housing Studies 17 (1): 71-82.

Sassler, S., A. Cunningham, and D.T. Lichter. 2009. Intergenerational patterns of union formation and relationship quality. Journal of Family Issues 30 (6): 757-786.

Settersten, R.A., Jr., and G.O. Hagestad. 1996. What's the latest? Cultural age deadlines for family transitions. The Gerontologist 36 (2): 178-188.

Settersten, R.A., Jr., and K.U. Mayer. 1997. The measurement of age, age structuring and the life course. Annual Review of Sociology 23 (1): 233-261.

Sigle-Rushton, W., J. Hobcraft, and K. Kiernan. 2005. Parental divorce and subsequent disadvantage: A cross-cohort comparison. Demography 42 (3): 427-446.

Smock, P.J., and C.R. Schwartz. 2020. The demography of families: A review of patterns and change. Journal of Marriage and Family 82 (1): 9-34.

Sobotka, T., V. Skirbekk, and D. Philipov. 2011. Economic recession and fertility in the developed world. Population and Development Review 37 (2): 267-306.

Soons, J.P.M., and M. Kalmijn. 2009. Is marriage more than cohabitation? Well-being differences in 30 European countries. Journal of Marriage and Family 71 (5): 1141-1157.

Uunk, W. 2004. The economic consequences of divorce for women in the European Union: The impact of welfare state arrangements. European Journal of Population 20 (3): 251-285.

Van Damme, M., M. Kalmijn, and W. Uunk. 2009. The employment of separated women in Europe: Individual and institutional determinants. European Sociological Review 25 (2): 183-197.

Van de Kaa, D.J. 1987. Europe's second demographic transition. Population Bulletin 42 (1). 2001. Postmodern fertility preferences: From changing value orientations to new behavior. In Global fertility transition, ed. R.A. Bulatao and J.B. Casterline, 290-331. New York: Population Council.

Vignoli, D., S. Drefahl, and G. De Santis. 2012. Whose job instability affects the likelihood of becoming a parent in Italy? A tale of two partners. Demographic Research S12 (2): 41-62.

Vignoli, D., V. Tocchioni, and S. Salvini. 2016. Uncertain lives: Insights into the role of job precariousness in union formation in Italy. Demographic Research 35 (10): 253-282.

Weber, M. 1968. Economy and society. New York: Bedminster.

Wilson, W.J. 1987. The truly disadvantaged: The inner city, the underclass, and public policy. Chicago: University of Chicago Press.

Wolfe, J.D. 2009. Age at first birth and alcohol use. Journal of Health and Social Behavior 50 (4): 395-409.

Wood, J., K. Neels, and T. Kil. 2014. The educational gradient of childlessness and cohort parity progression in 14 low fertility countries. Demographic Research 31 (46): 1365-1416.

Zaidi, B., and S.P. Morgan. 2017. The second demographic transition theory: A review and appraisal. Annual Review of Sociology 43 (1): 473-492. 
Open Access This chapter is licensed under the terms of the Creative Commons Attribution 4.0 International License (http://creativecommons.org/licenses/by/4.0/), which permits use, sharing, adaptation, distribution and reproduction in any medium or format, as long as you give appropriate credit to the original author(s) and the source, provide a link to the Creative Commons license and indicate if changes were made.

The images or other third party material in this chapter are included in the chapter's Creative Commons license, unless indicated otherwise in a credit line to the material. If material is not included in the chapter's Creative Commons license and your intended use is not permitted by statutory regulation or exceeds the permitted use, you will need to obtain permission directly from the copyright holder. 